\title{
Seed Germination responses of the medicinal herb Centella asiatica
}

\section{Anjana Devkota* and Pramod Kumar Jha}

\author{
Central Department of Botany, Tribhuvan University, Kirtipur, Kathmandu, Nepal
}

*Corresponding author: devkotaa@gmail.com; pkjhaprof@gmail.com; phone: 977-1-4331322, fax: 977-1- 4333515

Received: 23 October 2009; Accepted: 20 June 2010

\begin{abstract}
The effect of several environmental factors on germination of medicinal herb Centella asiatica was investigated. Freshly harvested seeds of $C$. asiatica did not germinate even after gibberellic acid $\left(\mathrm{GA}_{3}\right)$ treatment and exposure to different treatments with light qualities, while two-three months old seeds exhibited germination (82\%) without pre-treatment at warm environment $\left(25-30^{\circ} \mathrm{C}\right)$. $\mathrm{GA}_{3}$ treatment induced germination by two weeks earlier than in control. Germination was significantly $(p=0.001)$ higher in red and white light than in blue and far red light. In addition, germination of $C$. asiatica was sensitive towards the salt stress and was significantly inhibited at $6500 \mathrm{ppm} \mathrm{NaCl}$. The leaf leachates from invasive weeds Chromolaena odorata, Ageratum conyzoides, Parthenium hysterophorus and Xanthium strumarium showed inhibitory effects on seed germination of $C$. asiatica. Parthenium hysterophorus had significant effect $(\mathrm{p}<0.001)$ on seed germination. These data contribute for the establishing of an efficient protocol for $C$. asiatica cultivation.
\end{abstract}

Key Words: 2,3,5-triphenyltetrazolium chloride, Salinity, Leaf leachate, weeds, gibberellic acid

\section{INTRODUCTION}

Centella asiatica (L.) Urban (Fam. Apiaceae) is an important medicinal plant in Nepal (Devkota and Jha, 2008). Extract of Centella exerted anti-inflammatory and antifilarial effects and is used as memory enhancer and wound healer (Shukla et al., 1999). Clinical trials have also shown that it can help those with chronic venous insufficiency (Brinkaus et al., 2000). Medicinal properties of the plant led to its over exploitation. Centella asiatica propagates vegetatively as well as by seeds. Seeds offer genetic variation and ease of portability and storage as compared to vegetative propagules apart of resilience to draught (Brock et al., 2003).
Uniform stand establishment for Centella production is essential for maintaining profitable yields. Poor stands result from several factors including seed quality, environment, water, soil quality, site preparation, plant uniformity, irrigation practices and other management practices. Excessive use of chemical fertilizers and pesticides contribute to an increase of soil salinity which is one of the major obstacles in increasing crop production in the world (Serrano et al., 1999). It is important to establish seed germination requirements of important species such as $C$. asiatica, in order to understand the possible role of different environmental factors for the establishment in nature. Therefore this study focused on seed attributes and effects of salinity, pretreatments (i.e. warm water, $10 \%$ 
$\mathrm{HNO}_{3}, \mathrm{GA}_{3}$ treatments), extracts of alien species and light quality on seed germination of $C$. asiatica.

\section{MATERIALS AND METHODS}

Seed source and physical attribute: The Centella seeds were collected from natural population (agricultural land in Kirtipur during fallow period). Climate of Kirtipur, Kathmandu is sub tropical and monsoonic and the soil has slightly acidic nature. The seeds were collected during June 2006 and 2007. Seeds were dried in shade for a week and stored in hermetically sealed polythene pouches (Copeland, 1976) under ordinary storage condition at room temperature for subsequent germination studies.

Seed output per unit area was measured according to Zobel et al., (1987). The seed size was determined by measuring scale, whereas seed mass was determined by using an electric balance $(0.001 \mathrm{~g})$.

Seed viability: The seed coverings were removed manually and the decoated seeds were soaked in distilled water and kept in dark for $24 \mathrm{~h}$ before being treated with $0.1 \%$ solution of 2,3,5-triphenyltetrazolium chloride (TTC) for assessing the effects of various durations of storage on viability (Misra,1968).

Germination test: Germination of Centella asiatica was evaluated using 2-3 months old seeds by placing seeds in a Petri dish containing two layers of Whatman No. 1 filter paper, moistened with $10 \mathrm{ml}$ of distilled water or a treatment solution. The Petri dishes were placed on a table in the laboratory at room temperature. The average daily maximum and minimum room temperatures during the experiment were 30 and $20^{\circ} \mathrm{C}$, respectively. The Petri dishes were wrapped in two layers of aluminium foil to determine germination in complete darkness. All seeds except for pretreatment experiment were soaked in 10 ppm GA for 30 min before incubating in Petri dish for enhancing germination. Seed germination was monitored 2 days after the beginning of the experiment, with the criterion for germination being visible protrusion of the radicle. All sets of treatment and control contained four replicates, each of 30 seeds.
Effects of pre-treatments: Presoaking treatments used in the study were: different concentration of $\mathrm{GA}_{3}$, warm water, cold water and $10 \% \mathrm{HNO}_{3}$. Before placing in Petri dishes, seeds were soaked in 10,20,30,40, 50 and $100 \mathrm{ppm} \mathrm{GA}_{3}$ solution; 40 and $60^{\circ} \mathrm{C}$ warm water and cold water (at room temperature) for 30 min. For $10 \% \mathrm{HNO}_{3}$ treatment, after soaking the seeds were washed with distilled water three times before incubation in Petri dishes.

Effects of light: To study the effects of coloured light; petri dishes with seeds were covered by red and blue cellophane plastic till the completion of experiment.

Effect of Salt Stress: In order to determine the influence of salt stress on germination seeds of $\mathrm{C}$. asiatica were incubated in sodium chloride ( $\mathrm{NaCl}$ ) solutions of $0,500,1500$, $2500,3500,4500$ and 6500 ppm. The non-germinated seeds at $6500 \mathrm{ppm}$ were transferred to Petri dishes containing $5 \mathrm{ml}$ of distilled water and placed in the incubator as described previously. The seeds were rinsed before being transferred.

Phytotoxic effects of leaf leachates of alien plants: Four alien species, Chromolaena odorata, Parthenium hysterophorus, Ageratum conyzoides and Xanthium strumarium, were collected randomly in vegetative stage in a sunny mid day of July 2007 from Kirtipur. Leachates were prepared by immersing $10 \mathrm{~g}$ each of fresh plant materials (leaf, stem) in $100 \mathrm{ml}$ of distilled water in beaker separately and kept for $24 \mathrm{~h}$ at room temperature and filtered using muslin cloth as recommended by Tukey and Mecklenburg (1964). This filtrate was taken as stock solution with $10 \%$ of concentration and different concentration solution (i.e. 1 and $5 \%$ ) were made by dilution with distilled water and used for Petri dish bioassay with $C$. asiatica seeds.

Statistical Analyses: All experiments were conducted in a randomized complete block design. Treatments of each experiment were replicated three times and all experiments were repeated. The data from the repeated experiments were pooled before being subjected to ANOVA.

\section{RESULTS}

Seed attributes and viability: As shown in Table 1 Centella asiatica had 15 seeds per ramet which are brownish in colour 
and slightly kidney-shaped. The average length and breadth of seeds were 2.84 and $1.81 \mathrm{~mm}$, respectively. The mass of 100 air dried and water imbibed (24h) seeds were also determined. TTC test indicated $82 \%$ viability in freshly harvested seeds of C. asiatica. Seeds viability deteriorated as duration of storage increased and they became non-viable after storage for thirty months (Figure 1). Freshly harvested seeds of $C$. asiatica did not germinate even after $\mathrm{GA}_{3}$ treatment and incubation under different light qualities, whereas two-three months old seeds exhibited germination (82\%) without pre-treatment at warm environment $\left(25-30^{\circ} \mathrm{C}\right)$.

Table 1. Centella asiatica seeds output and characteristics

\begin{tabular}{lc}
\hline \multicolumn{1}{c}{ Seed attributes $^{\text {a }}$} & Values \\
\hline Seed colour & Brownish \\
Seed shape & Slightly kidney-shaped \\
Seed size & \\
i..seed width $(\mathrm{mm})$ & i. $1.81 \pm 0.2$ * \\
ii. seed length $(\mathrm{mm})$ & ii. $2.84 \pm 0.25$ * \\
No. of seeds/fruit & $3.0 \pm 1.0$ * \\
No of fruits/ramet & $5.0 \pm 2.0$ * \\
Seed output/ramet & $15.0 \pm 2.0$ * \\
Plant density/m ${ }^{2}$ & $32.0 \pm 3.0$ ** \\
Seed production/ $\mathrm{m}^{2}$ & $480.0 \pm 8.0$ ** \\
Weight of 100 air dried seeds $(\mathrm{g})$ & $0.13 \pm 0.02$ \\
Weight of 100 water imbibed seeds $(\mathrm{g})$ & $0.38 \pm 0.08$ \\
\hline The data represent mean $\pm \mathrm{SE}\left({ }^{*} \mathrm{n}=100 ;{ }^{* *} \mathrm{n}=30\right)$
\end{tabular}

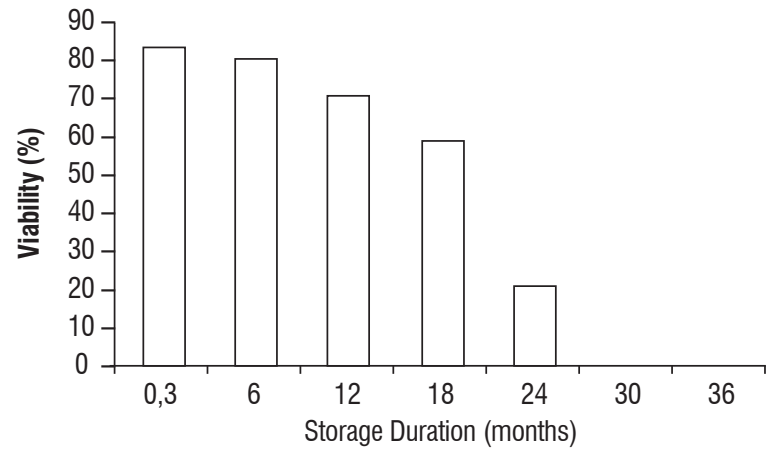

Figure 1.Viability of $C$. asiatica seeds on different storage duration.

Effects of different factors on germination: The effects of ten different pre-treatments on germination of seeds of Centella asiatica are shown in Figure 2. The germination percentage varied significantly among the treatments. Germination of seeds pretreated with $60^{\circ} \mathrm{C}$ water were significantly lower than germination of seeds pre-treated with $10 \% \mathrm{HNO}_{3}$ and seeds treated with different concentration of $\mathrm{GA}_{3}$. Among the different treatments of $\mathrm{GA}_{3}$, soaking seeds in $10 \mathrm{ppm}$ resulted in highest germination and was followed by $20 \mathrm{ppm}$. Increasing the concentration had no effect on germination (Figure 2). However $\mathrm{GA}_{3}$ treatment induced germination by nearly a week earlier than other treatments (Table 2) where seed germination occurred after second week of incubation. Treatments with $10 \% \mathrm{HNO}_{3}$ and warm water treatments $\left(40\right.$ and $60^{\circ} \mathrm{C}$ ) promoted the seed germination from third week of incubation, while it was started from fourth week in control (distilled water; Table 2).

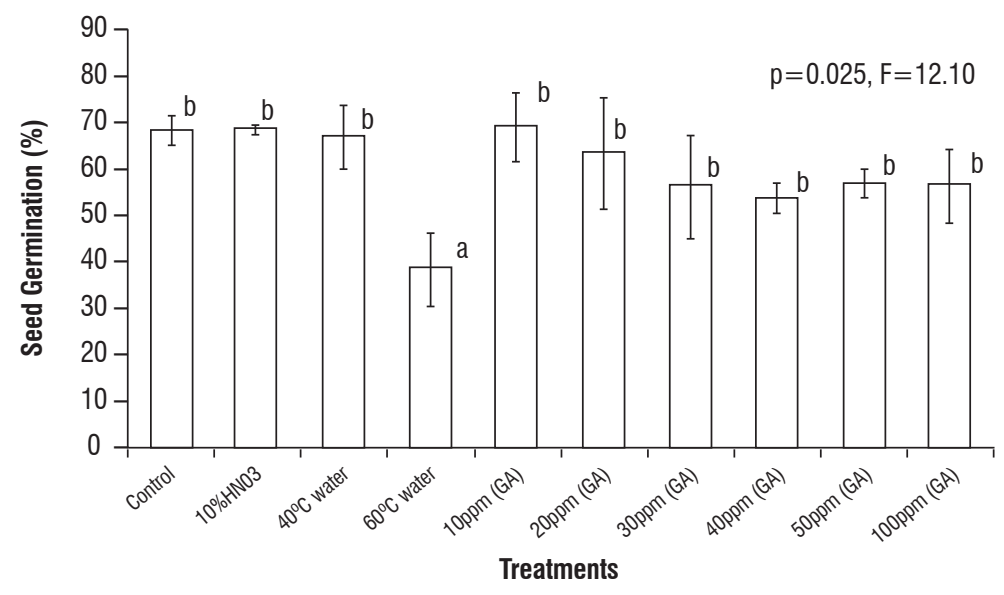

Figure 2. Effects of different pre-treatments on seed germination of $C$. asiatica after six weeks (bars marked with the same letter are not significantly different from the control, $p>0.05)$. 
Table 2. Effects of different pre-treatments on germination of Centella asiatica seeds.

\begin{tabular}{|c|c|c|c|c|c|c|}
\hline \multirow{3}{*}{ Treatments } & \multicolumn{6}{|c|}{ Seed Germination (\%) } \\
\hline & \multicolumn{6}{|c|}{ week } \\
\hline & $1^{\mathrm{st}}$ & $2^{\text {nd }}$ & $3^{\text {rd }}$ & $4^{\text {th }}$ & $5^{\text {th }}$ & $6^{\text {th }}$ \\
\hline Control & 0 & 0 & 0 & 4 & 48 & 68 \\
\hline $10 \%$ HNO3 & 0 & 0 & 20 & 65 & 65 & 68.33 \\
\hline $40^{\circ} \mathrm{C}$ water & 0 & 0 & 8 & 40 & 56 & 66.66 \\
\hline $60^{\circ} \mathrm{C}$ water & 0 & 0 & 8 & 18 & 30 & 38.33 \\
\hline $10 \mathrm{ppm} \mathrm{GA}$ & 0 & 20 & 65 & 65 & 65 & 69 \\
\hline $20 \mathrm{ppm} \mathrm{GA}$ & 0 & 5 & 35 & 35 & 45 & 63.33 \\
\hline $30 \mathrm{ppm} \mathrm{GA}{ }_{3}$ & 0 & 5 & 35 & 35 & 45 & 56 \\
\hline $40 \mathrm{ppm} \mathrm{GA_{3 }}$ & 0 & 20 & 40 & 50 & 52 & 53.33 \\
\hline $50 \mathrm{ppm} \mathrm{GA}$ & 0 & 15 & 50 & 50 & 56 & 56.66 \\
\hline $100 \mathrm{ppm} \mathrm{GA}$ & 0 & 10 & 20 & 40 & 40 & 56 \\
\hline
\end{tabular}

Effect of coloured light on germination: Significant differences $(p<0.001)$ in germination were observed when seeds were exposed to the different wave lengths of white light (blue, red and far red light) (Figure 3). The germination was slightly higher in red light and inhibited in blue and far red lights. The seeds were defective on germination in dark conditions.

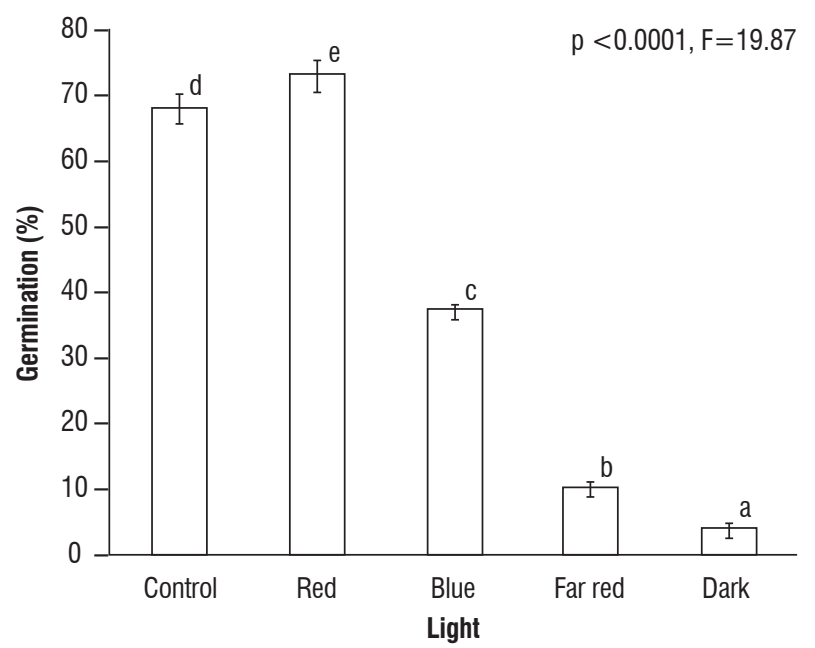

Figure 3. Final germination percentages of Centella asiatica seeds in different coloured light (observation at sixth week).

Effect of Salt Stress on Germination: Salinity significantly affected the germination percentage of $C$. asiatica $(p<0.001)$ (Figure 4). At salinities up to $3500 \mathrm{ppm} \mathrm{NaCl}$ germination rate ranged $70-73 \%$. The germination was inhibited by 57 and $89 \%$ at $4500 \mathrm{ppm}$ and $5500 \mathrm{ppm} \mathrm{NaCl}$ respectively, and completely abolished at $6500 \mathrm{ppm}$ salinity. When non-germinated seeds were removed from $6500 \mathrm{ppm}$ and placed in distilled water there was no germination recorded, indicating that seeds were irreversibly severely affected by exposure to conditions of high salinity and were not able to germinate later on even in favourable conditions.

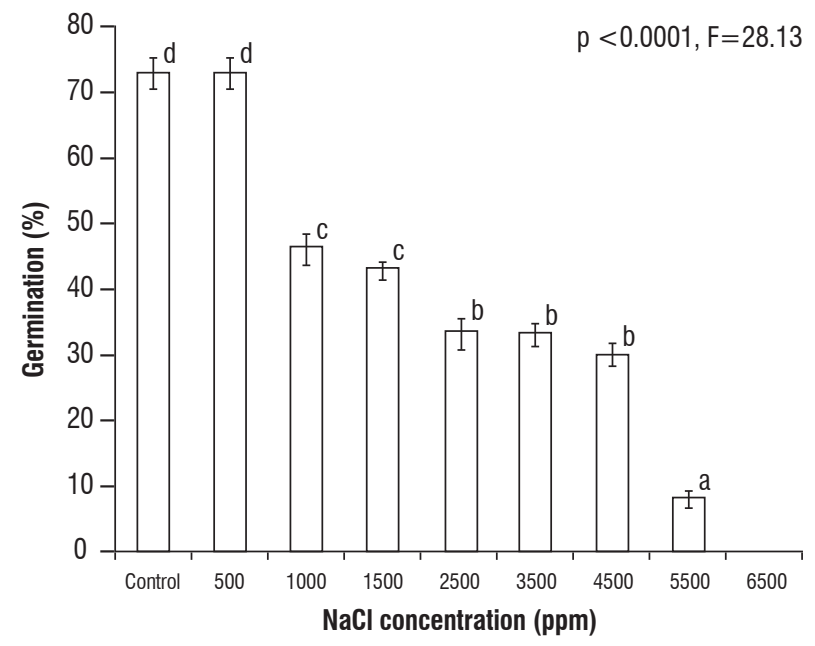

Figure 4. Germination of seeds of Centella asiatica in different concentration of $\mathrm{NaCl}$ (bars marked with the same letter are not significantly different at $p>0.05)$.

Phytotoxic effects of leaf leachates of alien plants: The germination of Centella asiatica seeds was sensitive to leaf leachates of different alien invasive weeds (Table 3) when 
compared to control. Highest percentage of germination of seeds was observed at control (88\%). Out of the four plants studied, concentrated leachates of Parthenium hysterophorus leachates exhibited drastic significantly higher $(p<0.001)$ inhibitory effects on germination (only $20 \%$ germination), and followed by Ageratum conyzoides 10\% extract where only $40 \%$ seeds germinated, while lowest inhibitory effect on germination was observed using Chromolaena odorata (Table 3).

Table 3. Effects of leaf leachates of some weeds plants on seed germination of $C$. asiatica.

\begin{tabular}{lcccccc}
\hline \multirow{2}{*}{ Treatments } & \multicolumn{7}{c}{ Germination (\%) \pm S.D. } \\
\cline { 2 - 7 } & 1st week & 2nd week & 3rd week & 4th week & 5th week & 6th week \\
\hline Control (0\%) & 0 & 0 & $5 \pm 1.0$ & $61.0 \pm 1.0$ & $88 \pm 1.0$ & $88 \pm 1.0$ \\
Chromolaena odorata (1\%) & 0 & 0 & $1.0 \pm 1.0$ & $35.0 \pm 2.0$ & $75 \pm 2.0$ & $75 \pm 2.0$ \\
Chromolaena odorata (5\%) & 0 & 0 & 0 & $20 \pm 1.0$ & $50 \pm 1.0$ & $50^{\star *} \pm 1.0$ \\
Chromolaena odorata (10\%) & 0 & 0 & 0 & $26 \pm 1.0$ & $56 \pm 1.0$ & $56^{\star *} \pm 2.0$ \\
Parthenium hysterophorus (1\%) & 0 & 0 & 0 & $30 \pm 2.0$ & $63 \pm 2.0$ & $63^{*} \pm 2.0$ \\
Parthenium hysterophorus (5\%) & 0 & 0 & 0 & $18 \pm 1.0$ & $51 \pm 1.0$ & $51^{\star *} \pm 1.0$ \\
Parthenium hysterophorus (10\%) & 0 & 0 & 0 & $6 \pm 1.0$ & $20 \pm 1.0$ & $20^{\star *} \pm 1.0$ \\
Ageratum conyzoides (1\%) & 0 & 0 & 0 & $03 \pm 1.0$ & $67 \pm 2.0$ & $67^{\star} \pm 2.0$ \\
Ageratum conyzoides (5\%) & 0 & 0 & 0 & $1 \pm 0$ & $56 \pm 1.0$ & $56^{\star *} \pm 1.0$ \\
Ageratum conyzoides (10\%) & 0 & 0 & 0 & 0 & $40 \pm 2.0$ & $40^{* *} \pm 2.0$ \\
Xanthium strumarium (1\%) & 0 & 0 & 0 & $16 \pm 1.0$ & $58 \pm 2.0$ & $65^{\star} \pm 2.0$ \\
Xanthium strumarium (5\%) & 0 & 0 & 0 & $1 \pm 0$ & $65 \pm 1.0$ & $65^{\star} \pm 1.0$ \\
Xanthium strumarium (10\%) & 0 & 0 & 0 & $1 \pm 0$ & $53 \pm 3.0$ & $53^{* *} \pm 3.0$ \\
\hline
\end{tabular}

Single $\left(^{*}\right)$ and double asterisks $\left(^{* *}\right)$ indicate values significantly different from control at $p=0.05$ and 0.001 , respectively.

\section{DISCUSSION}

The present study evaluated several aspects of $C$. asiatica seeds focusing on germination. Freshly collected seeds had the highest viability which declined progressively as the duration of storage increased. In general, deterioration of seeds with ageing results in the loss of viability and vigour which is usually due to the alteration in moisture content, changes in biochemical composition and increased leaching of electrolytes and low molecular weight substances during imbibitions (Kalpana and Rao, 1991; Hartmann et al., 1997). Pre-treatment significantly affected the mean cumulative germination percentage for the Centella asiatica (Figure 2, Table 2). Exposure to $\mathrm{GA}_{3}$ resulted in germination two weeks earlier than in control seeds, suggesting this treatment was effective in inducing metabolic activity in the embryo required for the initiation of germination process (Groot and Karssen,
1987). On a contrary, dipping seeds in warm water $\left(60^{\circ} \mathrm{C}\right)$ reduced nearly twice the total germination likely due to the destruction of certain enzymatic constituents present in the seed. Gill (1996) attributed the major cause of loss of viability to the scarcity of oxygen since water at high temperature has less gaseous content.

However Gill et al., (1996) reported 40\% germination of seeds of Delonix regia when immersed in hot water for 3 minutes. Pre-treatment of seeds by $10 \% \mathrm{HNO}_{3}$ and warm water $\left(30^{\circ} \mathrm{C}\right)$ also fastens the seed germination by one week earlier than the control (Table 2). This showed that these treatments enhance the metabolic activity required for germination. Jha and Jha (2002) also reported better germination of seeds of Alysicarpus vaginalis, Desmodium triflorum and Axonopus compressus after a treatment with $\mathrm{HNO}_{3}$ for 10 min when compared to control. 
Light significantly enhanced the germination of seeds of C. asiatica. In our study the seeds germinated significantly better in white and red light than in far-red or blue light or in the dark (Figure 3), as reported for some other species (Kiatsoonthorn and Tjitrosemito, 1992; Bell et al., 1999). Photoblastic seeds will germinate better in the open than under the forest canopy (Olatoye, 1965). In the open, solar radiation comes unhindered, moreover associated with this increase is the air and soil temperature. This best explain the exuberant growth of the seedlings of $C$. asiatica in the open land especially along the road sides and lawns at the onset of the rainy season (April-May) in Nepal. Thus, Centella seeds may not germinate well under a plant canopy where the FR/R ratio is high (Frankland, 1981). The mechanism of red/far-red light regulating seed germination via phytochrome system is well understood (Cone and Kendrick, 1986). The inhibitory effects of blue light and dark condition on $C$. asiatica seed germination is in agreement with previous reports (Jha and Jha, 2002). Taketay (1998) has reported germination in some photodormant Solanum species in the dark under the average amplitude of temperature fluctuation around $17^{\circ} \mathrm{C}$. In this study seeds of $C$. asiatica germinated in the dark considerably under the average amplitude of $20^{\circ} \mathrm{C}$. Least germination in the dark indicates that only some $C$. asiatica seeds can germinate even below the soil depth, or without light induction. This observation suggests that photo-dormance (no white light induction) is not expressed in Centella asiatica seed.

Germination of $C$. asiatica decreased with an increase in salinity and was substantially inhibited at $6500 \mathrm{ppm} \mathrm{NaCl}$ (Figure 4). Maximum germination was obtained in the nonsaline control. The results are in agreement with the work of Mondal et al. (1988) and Karim et al. (1992). It is also assumed that in addition to toxic effects of certain ions, higher concentration of salt reduces the water potential in the medium which hinders water absorption by germinating seeds and thus reduces germination (Maas and Nieman, 1978). It appears that a decrease in germination is related to salinity induced disturbance of metabolic process leading to increase in phenolic compounds (Ayaz et al., 2000). It is assumed that germination rate decrease with the decrease of the water movement into the seeds during imbibitions (Hadas, 1977). Salinity stress can affect seed germination through osmotic effects (Welbaum et al.,1990). Salt induced inhibition of seed germination could be attributed to osmotic stress or to specific ion toxicity (Huang and Redmann, 1995). Germination percentage also significantly decreased as the level of salinity of the medium increased (Gulzar et al., 2001; Mauromicale and Licandro, 2002).

The data on allelopathic effect of aqueous extracts of Parthenium hysterophorus, Chromolaena odorata, Ageratum conyzoides, and Xanthium strumarium exhibited significant inhibitory effects on seed germination of $C$. asiatica (Table 3 ). Similar findings were obtained by Oudhia (2000), who reported significant effect of Lantana camera leaf extract on germination of Melilotus alba which recorded lower germination than that of control. The minimum inhibitory effect of $C$. odorata (1\%) was reported, followed by $A$. conyzoides (1\%) and $X$. strumarium (1\%) extracts. Inhibitory effect was extract dosedependent, similarly to previous observations (Ballester et al., 1982; Daniel, 1999). Effects of leaf leachate of various weeds on germination, and radicle and plumule extension of field crops have also been reported earlier (Sugha, 1980; Singh et al., 1989). The inhibitory effects of studied plant species may be caused by allelopathy. These results are correlated with the findings of Kanchan and Jayachandra (1979) which found the allelopathic potential of many weed species on various field crop species in India. Inhibitory effects of leaf leachates of $P$. hysterophorus, $C$. odorata, A.conyzoids, $X$. strumarium on germination and growth of various weeds and crops have been reported earlier (Datta and Bandopadhaya, 1981, Sugha, 1980, Tefera, 2002). This could occur only when some allelochemicals present in the leaf extract prevented growth of embryo or caused the death. Further, Rice (1974) observed that many species of weeds produce toxins that are inhibitory to other weeds and often to themselves. The inhibitory effect of these species on germination has been attributed to phytotoxic chemicals released from the leaf litter and roots. Though $C$. asiatica plants grow along with weeds like $P$. hysterophorus, $C$. odorata, $X$. strumarium and A.conyzoids in same habitat, the inhibitory effect of these species on germination of $C$. asiatica seed may threaten its population in nature. This best explain the low density of $C$. asiatica in $P$. hysterophorus invaded site than in non invaded site (Karki, 2009).

\section{CONCLUSIONS}

Freshly harvested seeds of $C$. asiatica exhibited dormancy. The data revealed that pre-treatments with growth promoters $\left(\mathrm{GA}_{3}\right)$ positively affected Centella asiatica germination by reducing the time required for initiation of germination 
while salinity had adverse effect on the germination of $C$. asiatica seeds. Invasive weeds Parthenium hysterophorus, Chromolaena odorata, Artemisia and Xanthium exhibited inhibitory effects on germination, which may threaten the population density of $C$. asiatica plant in nature. The information provided in this study can be used as a practical contribution for establishment of scientifically organised nursery for cultivation of medicinal plant $C$. asiatica.

Acknowledgement: Partial financial support for this research from University Grants Commission (UGC), Nepal, is thankfully acknowledged. We are thankful to Mr. Bharat Babu Shrestha, Lecturer, Central Department of Botany, Tribhuvan University, for his help in statistical analysis.

\section{REFERENCES}

Ayaz FA, Kadioglu A, Turgut R (2000) Water stress effects on the content of low molecular weight carbohydrates and phenolic acids in Ctenanthe setosa (Rose.) Eichler. Can. J. Plant Sci. 80: 373-378.

Ballester A, Vieitez AM, Vieitez E (1982) Allelopathic potential of Erica vegans, Callunga vulgaris and Daboecia cantabrica. J. Chem. Ecol. 8: 851-857.

Bell DT, King LA, Plammer JA (1999) Ecophysiological effects of light quality and nitrate on seed germination of species from Western Australia. Aust. J. Ecol. 24: 2-10.

Brinkhaus B, Linder M, Schuppan D, Hahn EG (2000) Chemical pharmacological and clinical profile of the East Asian medicinal plant Centella asiatica. Phytomedicine.7:427-448.

Brock MA, Nielsen DL, Shiel RJ, Green JD, Langley JD(2003) Drought and aquatic community resilience: the role of eggs and seeds in sediments of temporary wetlands. Freshwater Biol.8: 1207-1218.

Cone JW, RE Kendrick (1986) Photocontrol of seed germination. In R.E. Kendrick and G.H.M. Kronenberg (eds.), Photomorphogenesis in Plants. Martinus Nijhoff Publishers, Dordrecht, pp. 443-446.

Copeland LO (1976) Principles of Seed Science and Technology. Burgess Publishing Company, Minnesota.

Daniel WG (1999) Historical review and current models of forest succession and interference, CRC Press LLC, pp.237-251.

Datta SC, Bandyopadhaya AK (1981) Proc. $8^{\text {th }}$ Asian Pacific Weed Sci. Soc. Conf. 1: 391-399.

Devkota A , Jha PK (2008) Biology and medicinal characteristics of Centella asiatica.In: Jha PK Karmacharya SB, Chettri MK., Thapa CB and Shrestha BB (ed.) Medicinal Plants in Nepal: An Anthology of Contemporary Research. Ecological Society (ECOS): Kathmandu, Nepal. pp. 68-80.

Frankland B (1981) Germination in shade. In H. Smith (ed.), Plants and the Daylight Spectrum. Academic Press, New York, pp. 187-203.

Groot SPC, Karssen CM (1987) Gibberellins regulate seed germination in tomato by endosperm weakening: a study with gibberellin-deficient mutants. Planta. 171(4):525-531.

Gill G S (1996) Why annual ryegrass is a problem in Australian agriculture. Plant Prot. Q. 11:193-195.

Gill LS, Jegede JRO, Ussani SWN (1996) Studies in the germination of Acacia franesina (L.) Leguminosae, J. Tree Sci. 5:92-99.
Gulzar S, Khan MA, Ungar IA (2001) Effect of salinity and temperature on the germination of Urochondra setulosa (Trin.) C. E. Hubbard, Seed Sci. Technol. 29: $21-29$.

Hadas A (1977) Water uptake and germination of leguminous seeds in soils of changing matrix and osmotic water potential. J. Exp. Bot. 28: 977-985.

Hartmann HT, Kester D, Davies FT, Geneve RL(1997) Plant Propagation: Principles and Practices (6th ed.).Prentice-Hall, Inc., New Jersey.

Huang J, Redmann RE (1995) Salt tolerance of Hordeum and Brassica species during germination and early seedling growth. Can. J. Plant Sci. 75 : 815-819.

Jha S, Jha PK (2006) Germination responses of some forage species of Biratnagar, Nepal.Ecoprint.13:49-60.

Kanchan SD, Jayachandra (1979) Allelopathic effect of Parthenium hysterophorus L.II.Leaching of inhibitors from aerial vegetative parts. Plant Soil. 53:61-66.

Kalpana RK, Rao VM (1991) Physiological and biochemical changes in stored seed of pigeon pea. J. Ind Bot. Soc. 70:70-76.

Karim MA, Utsunomlya N , Shigenaga S (1992) Effect of sodium chloride on germination and growth of hexaploid triticale at early seedling stage. Jpn. J. Crop Sci.61:279-284.

Karki D (2009) Ecological and Socio-Economic impacts of Parthenium hysterophorus L. invasion in two urban areas in Nepal. Central Department of Botany, Tribhuvan University, Kathmandu, Nepal. [M. Sc. Thesis]. 91p.

Kiatsoonthorn V, Tjitrosemito S (1992) Effect of light qualities and storage periods on the germination of Pennisetum polystachion seeds. Biotropica 5: 15-21.

Maas EV, Nieman RH (1978) Physiology of plant tolerance to salinity. In: Crop Tolerance and suboptimal land conditions, G. A. Jung (ed.) pp. 277-299.

Misra R (1968) Ecology. Workbook.Oxford and IBH Publishing Company, New Delhi.

Mauromicale G, Licandro P (2002) Salinity and temperature effects on germination, emergence and seedling growth of globe artichoke. Agronomie. 22: $443-450$.

Mondal TK , Bal AR, Dal S (1988). Effect of salinity on germination and seedling growth of different rice (Oryza sativa L.) cultivars. J. Indian Soc. Coastal Agric. Res.6: 91-97.

Olatoye ST (1965) The effect of light, prechilling and gibberellic acid on the germination of Chlorophora excelsa and Chlorophora regia. Nigerian J. Agri. 2:71-74.

Oudhia P (2000) Allelopathic effects of some obnoxious weeds on germination of Melilotus alba. Legume Res. 22: 133-134.

Rice EL (1974). Allelopathy. Academic press, New York, pp. 32-36.

Serrano R, Macia FC, Moreno V (1999). Genetic engineering of salt and drought tolerance with yeast regulatory genes. Sci. Hortic. 78: 261-269.

Shukla A, Rasik AM, Dhavan BN (1999) Asiaticoside induced elevation of antioxidant levels in healing wounds. Phytotherapic Res. 13:50-54.

Singh SP, UR Pal, Luka K (1989) Allelopathic effects of three serious weeds of Nigerin savanna on germination and seedling vigour of soybean and maize. J. Agr. Crop Sci. 162: 236-240.

Sugha SK (1980) An assessment of allelopathic potentials of three common weeds. Food Far. and Agric. 11: 261-262.

Taketay D (1998) Environmental factors that control the germination of five Solanum species from Ethiopia. Trop. Ecol. 39(1):79-87.

Tefera T (2002) Allelopathic effects of Parthenium hysterophorus extracts on seed germination and seedling growth of Eragrostis tef (Zucc.) Trotter, J. Agr Crop Sci. 188(5):306-310. 
Tukey HBJr, Mecklenburg RA (1964) Leaching of metabolites from foliage, subsequent reabsorption and redistribution of the leachate in plants. Ann. Bot. 51:737-743.

Welbaum GE, Tissaoui T, Bradford KJ (1990) Water relations of seed development and germination in muskmelon (Cucumis melo L.). III. Sensitivity of germination to water potential and abscisic acid during development. Plant Physiol. 92: 1029-1037.

Zobel DB, Jha PK, Behan MJ, Yadav UKR (1987) A Practical Manual for Ecology. Ratna Book Distributor, Kathmandu. 